\title{
Completeness of coronary revascularization and survival: Impact of age and off-pump surgery
}

\author{
Shuab Omer, MD, ${ }^{\mathrm{a}, \mathrm{b}}$ Lorraine D. Cornwell, MD, ${ }^{\mathrm{a}, \mathrm{b}}$ Todd K. Rosengart, MD, ${ }^{\mathrm{a}, \mathrm{b}, \mathrm{c}}$ Rosemary F. Kelly, MD, ${ }^{\mathrm{d}}$ \\ Herbert B. Ward, MD, ${ }^{d}$ William L. Holman, MD, ${ }^{e}$ and Faisal G. Bakaeen, MD ${ }^{\mathrm{a}, \mathrm{b}, \mathrm{c}}$
}

Objectives: We conducted a multicenter observational cohort study of the effect of completeness of revascularization on long-term survival after coronary artery bypass grafting. We also investigated the impact of age and off-pump surgery.

\begin{abstract}
Methods: The Veterans Affairs Continuous Improvement in Cardiac Surgery Program was used to identify all patients $(\mathrm{N}=41,139)$ with left main and 3-vessel coronary artery disease who underwent nonemergency coronary artery bypass grafting from October 1997 to April 2011. The primary outcome measure, all-cause mortality, was compared between patients with complete revascularization and patients with incomplete revascularization. Survival functions were estimated with the Kaplan-Meier method and compared by using the log-rank test. Propensity scores calculated for each patient were used to match 5509 patients undergoing complete revascularization to 5509 patients undergoing incomplete revascularization. A subgroup analysis was performed in patients aged at least 70 years and patients who underwent off-pump coronary artery bypass grafting.
\end{abstract}

Results: In the unmatched groups, several risk factors were more common in the incomplete revascularization group, as was off-pump coronary artery bypass grafting. In the matched groups, risk-adjusted mortality was higher in the incomplete revascularization group than in the complete revascularization group at 1 year $(6.96 \%$ vs $5.97 \%$; risk ratio [RR], $1.17 ; 95 \%$ confidence interval $[\mathrm{CI}], 1.01-1.34), 5$ years $(18.50 \%$ vs $15.96 \%$; RR, 1.16; 95\% CI, 1.07-1.26), and 10 years (32.12\% vs $27.40 \%$; RR, 1.17 ; $95 \%$ CI, $1.11-1.24)$, with an overall hazard ratio of $1.18(95 \% \mathrm{CI}, 1.09-1.28 ; P<.0001)$. The hazard ratio for patients aged 70 years or more was $1.125(95 \% \mathrm{CI}, 1.001-1.263 ; P=.048)$. The hazard ratio was 1.47 (95\% CI, 1.303-1.655) for the unmatched off-pump coronary artery bypass grafting group and 1.156 (95\% CI, 1.000-1.335) for the matched off-pump coronary artery bypass grafting group.

Conclusions: Incomplete revascularization is associated with decreased long-term survival, even in elderly patients. Surgeons should consider these findings when choosing a revascularization strategy, particularly if off-pump coronary artery bypass grafting is contemplated. (J Thorac Cardiovasc Surg 2014;148:1307-15)

\section{Supplemental material is available online.}

The management of coronary artery disease (CAD) has evolved significantly since the first coronary artery bypass

\footnotetext{
From the Division of Cardiothoracic Surgery, ${ }^{\mathrm{a}}$ Michael E. DeBakey Department of Surgery, Baylor College of Medicine, Houston, Tex; The Michael E. DeBakey Veterans Affairs Medical Center, ${ }^{\mathrm{b}}$ Houston, Tex; Department of Cardiovascular Surgery, ${ }^{c}$ The Texas Heart Institute, Houston, Tex; Division of Cardiothoracic Surgery, ${ }^{\mathrm{d}}$ University of Minnesota and Minneapolis Veterans Affairs Medical Center, Minneapolis, Minn; and Department of Cardiothoracic Surgery, ${ }^{\mathrm{e}}$ University of Alabama and Birmingham Veterans Medical Center, Birmingham, Ala.

Funding: The Michael E. DeBakey VA Medical Center. There are no conflicts of interest to report.

Disclosures: Authors have nothing to disclose with regard to commercial support.

Received for publication Oct 4, 2013; revisions received Dec 11, 2013; accepted for publication Dec 30, 2013; available ahead of print Feb 9, 2014

Address for reprints: Shuab Omer, MD, Baylor College of Medicine/Michael E. DeBakey VA Medical Center, Mail code 112/OCL, 2002 Holcombe Blvd, Houston, TX 77030 (E-mail: Shuab.Omer@bcm.edu).

0022-5223/\$0.00

Published by Elsevier Inc. on behalf of The American Association for Thoracic Surgery

http://dx.doi.org/10.1016/j.jtcvs.2013.12.039
}

grafting (CABG) was performed by Favaloro $^{1}$ in 1967 and the first percutaneous transluminal coronary angioplasty was performed by Gruntzig ${ }^{2}$ in 1977 . Since then, most cardiac surgeons have held the belief that completely revascularizing all significantly diseased vessels would be ideal. However, with recent better understanding of the pathogenesis and natural history of CAD, there has been a realization that this approach to revascularization might not be as straightforward as believed or even realistically achievable in all cases.

Decision-making regarding coronary intervention historically has been based on the degree of stenosis of the coronary vessels $(>50 \%$ stenosis in the major arterial territories) and the diameter of the target vessel $(>1.5$ $\mathrm{mm})$. This still holds true in the majority of cases today, but it is now clear that it is not always possible to completely revascularize all diseased segments for anatomic reasons (small diameter; heavy calcification; and, in the case of percutaneous coronary intervention [PCI], chronic total occlusion) or patient comorbidities that make a longer intervention infeasible. ${ }^{3}$ Thus, various groups have coined 


$$
\begin{aligned}
& \text { Abbreviations and Acronyms } \\
& \begin{aligned}
\text { CABG } & =\text { coronary artery bypass grafting } \\
\text { CAD } & =\text { coronary artery disease } \\
\text { CCS } & =\text { Canadian Cardiovascular Society } \\
\text { CI } & =\text { confidence interval } \\
\text { CR } & =\text { complete revascularization } \\
\text { HR } & =\text { hazard ratio } \\
\text { IR } & =\text { incomplete revascularization } \\
\text { LAD } & =\text { left anterior descending } \\
\text { LM } & =\text { left main } \\
\text { NYHA } & =\text { New York Heart Association } \\
\text { PCI } & =\text { percutaneous coronary intervention } \\
\text { RR } & =\text { risk ratio } \\
\text { VA } & =\text { Veterans Affairs } \\
\text { VASQIP } & =\text { Veterans Affairs Surgical Quality } \\
& \text { Improvement Project }
\end{aligned}
\end{aligned}
$$

terms such as "complete revascularization," "reasonable incomplete revascularization," and "unreasonable incomplete revascularization" on the basis of functional and anatomic criteria. ${ }^{3-7}$ Others have coined the terms "traditional complete revascularization" 8 and "functional complete revascularization.",

The American College of Cardiology/American Heart Association guidelines on CABG do not make clear recommendations regarding completeness of revascularization. ${ }^{10}$ Most studies to date have been single-center series with a limited number of patients. In addition, the impact of completeness of revascularization on long-term survival has not been adequately evaluated.

Therefore, we looked at a large national database of US veteran patients who underwent complete revascularization (CR) and compared their outcomes with those of patients who underwent incomplete revascularization (IR). In addition, we evaluated any impact that advanced age might have had on the outcomes of the 2 revascularization strategies and whether off-pump CABG was associated with IR.

\section{MATERIALS AND METHODS \\ Patients and Methods}

This study was approved by the institutional review board that serves Baylor College of Medicine and the Michael E. DeBakey VA Medical Center. The requirement for informed consent was waived. The Veterans Affairs (VA) Surgical Quality Improvement Project (VASQIP) is part of the VA Surgical Quality Improvement Program and prospectively collects risk and outcomes data on all patients who undergo cardiac operations at any of the 40 VA cardiac surgery centers in this nonvoluntary database. ${ }^{11} \mathrm{We}$ received approval for the study from the Department of Veterans Affairs Surgical Quality Use Data Group and identified all patients with 3-vessel or left main (LM) disease $(\mathrm{N}=41,139)$ who underwent primary isolated nonemergency CABG with conventional sternotomy at the participating VA hospitals between October 1997 and April 2011. The VASQIP's data fields and definitions were used. Patients who underwent reoperations and combined procedures were excluded. CR was achieved when the number of distal bypasses equaled or exceeded the total number of vessels with stenosis $50 \%$ or greater. Data regarding stenosis were available for the LM and the 3 major coronary vessels (left anterior descending [LAD], circumflex, and right). Isolated LM stenosis required at least 2 bypasses to achieve CR. The VASQIP database had complete vital status data, and time to death from the date of the operation was computed for patients who died before May 17, 2011. Patients who did not die before this date were censored.

\section{Statistics}

The primary outcome measure was all-cause mortality. Mortality was compared between patients with CR and IR. To adjust for baseline characteristic differences between $\mathrm{CR}$ and IR, we performed propensity score matching. To compute the propensity score, variables that were statistically significant in univariate analyses or clinically relevant were included in the logistic regression model. Covariates used for propensity scoring included age, diabetes, prior myocardial infarction, chronic obstructive pulmonary disease, sex, body mass index, peripheral vascular disease, cerebral vascular disease, serum creatinine, current smoking status, functional status, New York Heart Association (NYHA) class, Canadian Cardiovascular Society (CCS) angina class, American Society of Anesthesiology class, priority of surgical intervention, current digoxin use, pulmonary rales, PCI, cardiomegaly, and year of operation.

A greedy match algorithm using the propensity scores matched 5509 patients who underwent $C R$ with 5509 patients who underwent IR. We assessed the success of the propensity score matching post hoc by using the Student $t$ test for continuous variables and the chi-square test for categoric variables. The matched CR and IR patients were similar on all variables except current digoxin use. In addition, there were small but statistically significant differences in the prevalence of LM and 3-vessel diseases that were adjusted for by sensitivity analysis. Survival functions were estimated by using the KaplanMeier method and compared by using the log-rank test.

We calculated the risk ratio (RR) with a $95 \%$ confidence interval (CI) at specific time points by using the estimated rates of survival for the CR and IR patients. Differences between these ratios were assessed for significance with the $z$ ratio. In addition, we used Cox proportional hazard models to estimate the hazard ratio (HR) between CR and IR patients in both the unmatched and the propensity score-matched groups.

A subgroup analysis was performed for those patients who were aged at least 70 years and patients who underwent off-pump CABG. We also ran a logistic model to determine whether off-pump CABG was associated with IR. To perform sensitivity analysis, we narrowed the CR group to only those patients whose number of distal bypasses equaled or exceeded the total number of vessels with stenosis $75 \%$ or greater. All statistical analyses were conducted with SAS 9.1 software (SAS Institute Inc, Cary, NC).

\section{RESULTS \\ Entire Cohort}

Of the 41,139 patients, 5709 (13.9\%) underwent IR and $35,430(86.1 \%)$ underwent CR. Their mean age was $64.1 \pm$ 9.0 years. Table 1 shows the major differences in the unmatched cohorts, including a higher prevalence of chronic obstructive pulmonary disease, peripheral vascular disease, cerebral vascular disease, ejection fraction, and NYHA class III and IV in the IR group. There was a lower prevalence of CCS angina III and IV in the IR group. Of note, off-pump CABG was more frequent in the IR cohort. On multivariate regression logistic analysis, off-pump CABG was a predictor of IR ( $\mathrm{C}$ value receiver operating characteristic $=.66$ ). 
TABLE 1. Entire cohort: Patient demographics and risk profile

\begin{tabular}{|c|c|c|c|c|}
\hline Variable & Total $N=41,139(\%)$ & Incomplete $n=5709(\%)$ & Complete $n=35,430(\%)$ & $P$ value \\
\hline Age $(y)$ & $64.1 \pm 9.0$ & $65.0 \pm 9.3$ & $64.0 \pm 9.0$ & $<.0001$ \\
\hline Gender $=$ male & $40,781(99.1)$ & $5648(98.9)$ & $35,133(99.2)$ & .082 \\
\hline Body mass index $\left(\mathrm{kg} / \mathrm{m}^{2}\right)$ & $29.3 \pm 5.4$ & $29.2 \pm 5.5$ & $29.3 \pm 5.4$ & .77 \\
\hline Chronic obstructive pulmonary disease & $10,273(25.0)$ & $1687(29.6)$ & $8586(24.2)$ & $<.0001$ \\
\hline Peripheral vascular disease & $10,438(25.4)$ & $1819(31.9)$ & $8619(24.3)$ & $<.0001$ \\
\hline Cerebral vascular disease & 9276 (22.6) & $1517(26.6)$ & 7759 (21.9) & $<.0001$ \\
\hline Serum creatinine $(\mathrm{mg} / \mathrm{dL})$ & $1.2 \pm 0.8$ & $1.3 \pm 1.0$ & $1.2 \pm 0.7$ & $<.0001$ \\
\hline Diabetes & & & & $<.0001$ \\
\hline No & $24,299(59.1)$ & $3244(56.8)$ & $21,055(59.4)$ & \\
\hline Oral & $9765(23.7)$ & $1360(23.8)$ & 8405 (23.7) & \\
\hline Insulin & $7072(17.2)$ & 1105 (19.4) & $5967(16.8)$ & \\
\hline Serum albumin $\geq 3.5 \mathrm{~g} / \mathrm{dL}$ & $27,251(80.1)$ & $3749(78.7)$ & $23,502(80.3)$ & .013 \\
\hline Current smoker & $11,935(29.0)$ & $1625(28.5)$ & $10,310(29.1)$ & .32 \\
\hline Ejection fraction $\leq 34 \%$ & $3081(10.3)$ & $536(12.1)$ & $2545(10.0)$ & $<.0001$ \\
\hline Functional status $=$ independent & $36,279(88.2)$ & $4863(85.2)$ & $31,416(88.7)$ & $<.0001$ \\
\hline Prior myocardial infarction & $21,311(51.8)$ & $3040(53.3)$ & $18,271(51.6)$ & .019 \\
\hline Prior $\mathrm{PCI}^{*}$ & $363(0.9)$ & $81(1.4)$ & $282(0.8)$ & $<.0001$ \\
\hline Preoperative use of IABP & $1644(4.0)$ & $234(4.1)$ & $1410(4.0)$ & .67 \\
\hline NYHA class & & & & $<.0001$ \\
\hline $\mathrm{I} / \mathrm{II}$ & $29,843(72.6)$ & $3951(69.2)$ & $25,892(73.1)$ & \\
\hline III/IV & $11,284(27.4)$ & $1757(30.8)$ & 9527 (26.9) & \\
\hline CCS angina class & & & & .0011 \\
\hline $\mathrm{I} / \mathrm{II}$ & $13,799(33.6)$ & $2023(35.4)$ & $11,776(33.3)$ & \\
\hline III/IV & $27,327(66.5)$ & $3685(64.6)$ & $23,642(66.8)$ & \\
\hline Current digoxin use & $1936(4.7)$ & $324(5.7)$ & $1612(4.6)$ & .0002 \\
\hline ASA class V & $28(0.1)$ & $6(0.1)$ & $22(0.1)$ & .25 \\
\hline Surgical priority $=$ nonelective & $6009(14.6)$ & $739(12.9)$ & $5270(14.9)$ & .0001 \\
\hline Coronary disease & & & & $<.0001$ \\
\hline 3-vessel disease & $28,504(69.3)$ & $4061(71.1)$ & $24,443(69.0)$ & \\
\hline Isolated LM disease & $523(1.3)$ & $46(0.8)$ & $477(1.4)$ & \\
\hline LM and other vessel(s) & $12,112(29.4)$ & $1602(28.1)$ & $10,510(29.7)$ & \\
\hline
\end{tabular}

Data presented as number (\%) or mean \pm standard deviation. ASA, American Society of Anesthesiology; CCS, Canadian Cardiovascular Society; IABP, intra-aortic balloon pump; $L M$, left main; NYHA, New York Heart Association; $P C I$, percutaneous coronary intervention. *Performed within 72 hours of coronary artery bypass grafting.

There was greater mortality in the IR group than in the CR group at 30 days $(2.64 \%$ vs $2.04 \% ; P=.0031)$ and at 1 year $(7.02 \%$ vs $4.99 \%), 3$ years $(12.40 \%$ vs $9.28 \%)$, 5 years $(18.62 \%$ vs $14.34 \%)$, and 10 years $(32.14 \%$ vs $26.42 \%)(P<.0002$ for all time periods after 30 days $)$ (Figure 1, A).

\section{Matched Group}

Of a total of 11,018 patients (mean age, $65.0 \pm 9.3$ years), 5509 underwent IR and 5509 underwent CR. Patients were well matched for comorbidities and clinical characteristics, although the distribution of their CAD was somewhat different (Table 2).

The median duration of follow-up was 6.61 years (interquartile range, 6.51-6.72 years). Perioperative mortality between the IR and $\mathrm{CR}$ groups was $2.63 \%$ versus $2.25 \%$ $(P=.20)$. There were significant differences in riskadjusted mortality between the IR and CR groups at 1 year $(6.96 \%$ vs $5.97 \%$; RR, 1.17 ; 95\% CI, 1.01-1.34), 5 years $(18.50 \%$ vs $15.96 \%$; RR, 1.16; 95\% CI, 1.07-1.26), and 10 years $(32.12 \%$ vs $27.40 \%$; RR, $1.17 ; 95 \% \mathrm{CI}$, 1.11-1.24) (Figure 1, B). Overall, the HR for IR versus CR was 1.18 (95\% CI, 1.09-1.28; $P<.0001)$. These findings were confirmed by a sensitivity analysis in which $75 \%$ or greater stenosis was the cutoff for bypassing a coronary vessel.

\section{Patients Aged 70 Years or More}

In the unmatched subgroup aged 70 years or more (Figure 2, $A$ ), there was no significant difference in perioperative mortality between IR and CR $(4.04 \%$ vs $3.25 \%$; $P=.078)$. However, there was a significant difference in mortality between IR and CR at 1 year $(11.09 \%$ vs $8.61 \%), 3$ years $(18.18 \%$ vs $15.04 \%)$, 5 years $(27.28 \%$ vs $22.90 \%)$, and 10 years $(45.19 \%$ vs $39.35 \%)$ $(P<.0002$ for all $)$.

In the matched subgroup aged 70 years or more (Figure 2, $B)$, there was no statistically significant difference in mortality between IR and CR perioperatively $(4.04 \%$ vs $3.55 \% ; P=.44)$, at 1 year $(11.05 \%$ vs $9.43 \% ; P=.10)$, 


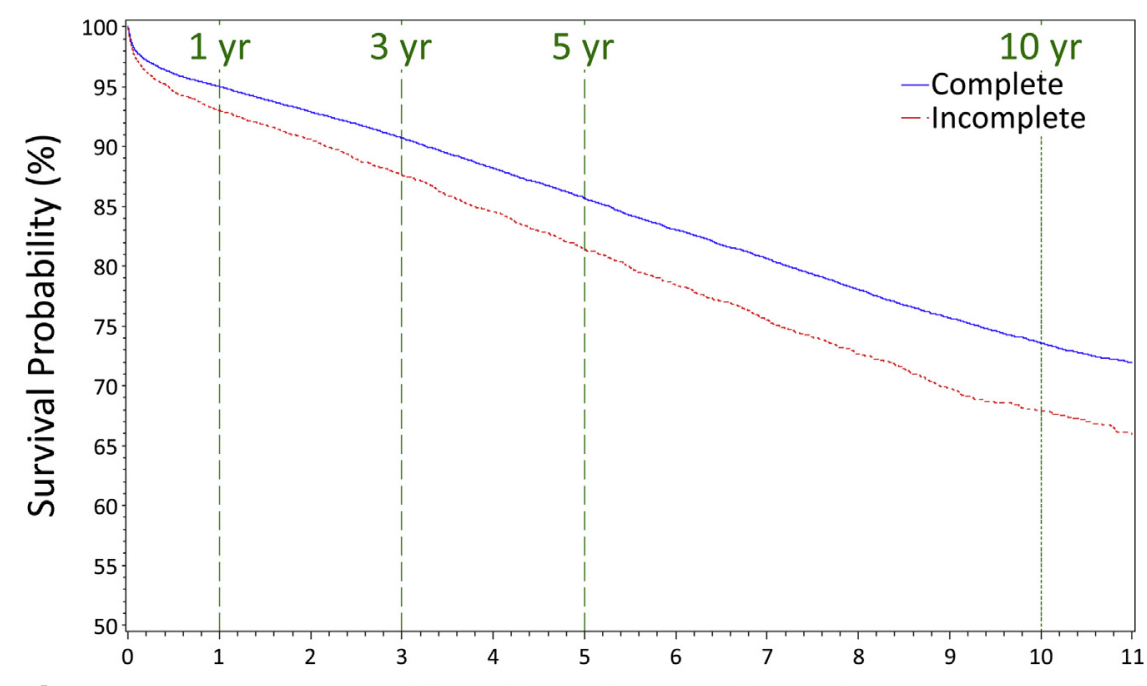

A Time Since Surgery (years)

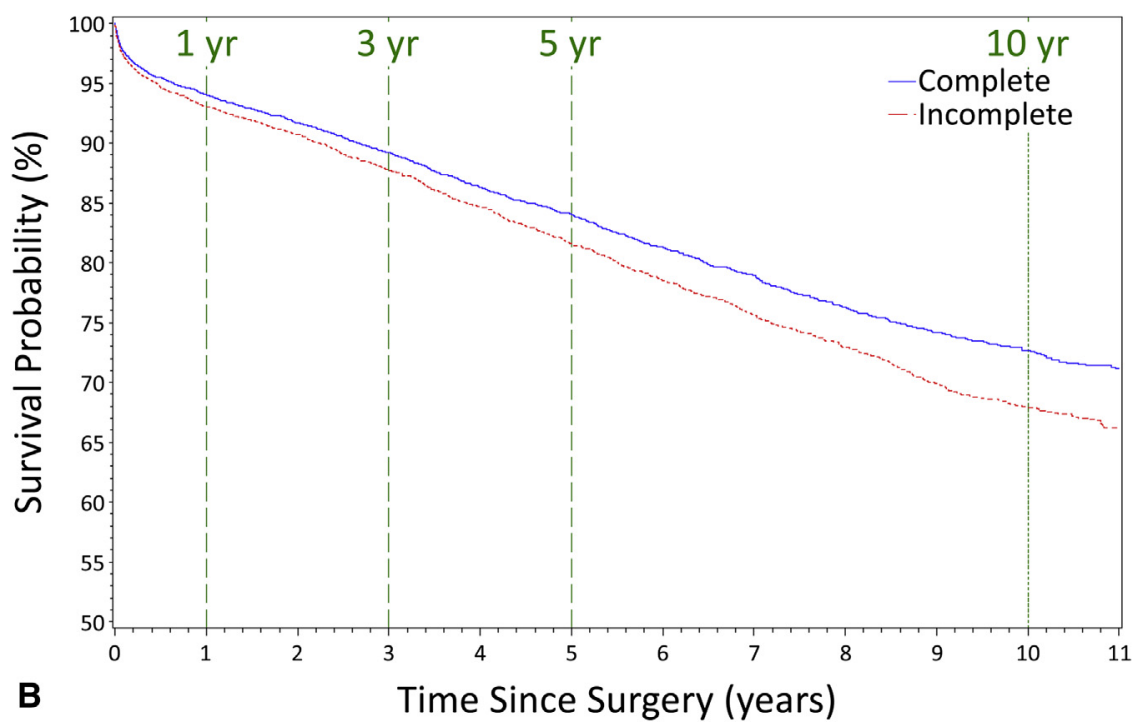

FIGURE 1. Entire cohort: Survival of patients undergoing CR versus IR in the (A) unmatched and (B) propensity-matched cohorts.

at 3 years $(18.13 \%$ vs $16.73 \% ; P=.26)$, or at 5 years $(27.04 \%$ vs $24.37 \% ; P=.064)$. However, we noticed a significant difference in mortality between IR and CR at 10 years $(45.06 \%$ vs $40.70 \% ; P=.008)$. The HR for IR versus $\mathrm{CR}$ for matched patients aged 70 years or more was 1.125 (95\% CI, 1.001-1.263; $P=.048)$.

\section{Unmatched Patients Undergoing On-pump and Off- pump Coronary Artery Bypass Grafting}

Of the 34,772 patients in the on-pump CABG cohort, 30,939 had CR and 3833 had IR. In the off-pump cohort, 4491 patients had CR and 1876 had IR.

In the unmatched on-pump CABG group (Figure E1, A), there was a statistically significant difference in mortality between IR and CR perioperatively $(2.69 \%$ vs $2.06 \%$; RR, $1.31 ; 95 \%$ CI, $1.06-1.60 ; P=.011)$, at 1 year $(7.10 \%$ vs $5.08 \%$; RR, $1.40 ; 95 \%$ CI, $1.23-1.58 ; P=.0002)$, at 3 years $(12.09 \%$ vs $9.39 \%$; RR, $1.9 ; 95 \%$ CI, $1.17-1.41$; $P=.0002)$, at 5 years $(18.01 \%$ vs $14.41 \%$; RR, 1.25 ; 95\% CI, $1.16-1.34 ; P=.0003)$, and at 10 years $(31.21 \%$ vs $26.60 \%$; RR, $1.17 ; 95 \%$ CI, $1.12-1.23 ; P=.0002)$. The overall HR was 1.249 (95\% CI, 1.163-1.342).

In the unmatched off-pump group (Figure E1, $B$ ), there was a statistically significant difference in mortality between IR and CR perioperatively $(2.56 \%$ vs $1.54 \%$; RR, $1.66 ; 95 \%$ CI, $1.15-2.39 ; P=.0056)$, at 1 year $(6.92 \%$ vs $4.40 \%$; RR, $1.57 ; 95 \% \mathrm{CI}, 1.27-1.95 ; P=.0002)$, at 3 years $(13.12 \%$ vs $8.48 \%$; RR, $1.55 ; 95 \%$ CI, $1.33-1.80$; $P=.0002)$, at 5 years $(20.02 \%$ vs $13.95 \%$; RR, 1.44 ; $95 \% \mathrm{CI}, 1.28-1.61 ; P=.0002)$, and at 10 years $(34.77 \%$ vs $25.06 \%$; RR, $1.39 ; 95 \% \mathrm{CI}, 1.28-1.50 ; P=.0002)$. The overall HR was 1.47 (95\% CI, 1.303-1.655). 
TABLE 2. Propensity-matched patients: Patient demographics and risk profile

\begin{tabular}{|c|c|c|c|c|}
\hline Variable & Total $\mathbf{n}=11,018(\%)$ & Incomplete $\mathbf{n}=\mathbf{5 5 0 9}(\%)$ & Complete $\mathbf{n}=\mathbf{5 5 0 9}(\%)$ & $P$ value \\
\hline Age (y) & $65.0 \pm 9.3$ & $65.0 \pm 9.3$ & $64.9 \pm 9.2$ & .70 \\
\hline Gender $=$ male & $10,912(99.0)$ & $5452(99.0)$ & $5460(99.1)$ & .43 \\
\hline Body mass index $\left(\mathrm{kg} / \mathrm{m}^{2}\right)$ & $29.2 \pm 5.4$ & $29.3 \pm 5.5$ & $29.1 \pm 5.3$ & .25 \\
\hline Chronic obstructive pulmonary disease & $3284(29.8)$ & $1621(29.4)$ & $1663(30.2)$ & .38 \\
\hline Peripheral vascular disease & $3511(31.9)$ & $1737(31.5)$ & $1774(32.2)$ & .45 \\
\hline Cerebral vascular disease & $2928(26.6)$ & $1460(26.5)$ & $1468(26.7)$ & .86 \\
\hline Serum creatinine $(\mathrm{mg} / \mathrm{dL})$ & $1.3 \pm 0.9$ & $1.3 \pm 1.0$ & $1.3 \pm 0.9$ & .66 \\
\hline Diabetes & & & & .98 \\
\hline No & $6259(56.8)$ & $3125(56.7)$ & $3134(56.9)$ & \\
\hline Oral & $2620(23.8)$ & $1312(23.8)$ & $1308(23.7)$ & \\
\hline Insulin & $2139(19.4)$ & $1072(19.5)$ & $1067(19.4)$ & \\
\hline Serum albumin $\geq 3.5 \mathrm{~g} / \mathrm{dL}$ & $7226(79.1)$ & $3632(78.9)$ & $3594(79.3)$ & .63 \\
\hline Current smoker & $3134(28.4)$ & $1576(28.6)$ & $1558(28.3)$ & .70 \\
\hline Ejection fraction $\leq 34 \%$ & $1104(12.5)$ & $532(12.0)$ & $572(13.0)$ & .18 \\
\hline Functional status $=$ independent & $9440(85.7)$ & $4704(85.4)$ & $4736(86.0)$ & .38 \\
\hline Prior myocardial infarction & $5883(53.4)$ & $2947(53.5)$ & $2936(53.3)$ & .83 \\
\hline Prior PCI* & $156(1.4)$ & $80(1.5)$ & $76(1.4)$ & .75 \\
\hline Preoperative use of IABP & $441(4.0)$ & $226(4.1)$ & $215(3.9)$ & .59 \\
\hline NYHA class & & & & .85 \\
\hline $\mathrm{I} / \mathrm{II}$ & $7609(69.1)$ & $3809(69.1)$ & $3800(69.0)$ & \\
\hline III/IV & $3409(30.9)$ & $1700(30.9)$ & $1709(31.0)$ & \\
\hline CCS angina class & & & & .97 \\
\hline $\mathrm{I} / \mathrm{II}$ & $3872(35.1)$ & $1937(35.2)$ & $1935(35.1)$ & \\
\hline III/IV & $7146(64.9)$ & $3572(64.8)$ & $3574(64.9)$ & \\
\hline Current digoxin use & $563(5.1)$ & $312(5.7)$ & $251(4.6)$ & .0083 \\
\hline ASA class V & $8(0.1)$ & $5(0.1)$ & $3(0.1)$ & .48 \\
\hline Surgical priority $=$ nonelective & $1408(12.8)$ & $710(12.9)$ & $698(12.7)$ & .73 \\
\hline Coronary disease & & & & $<.0001$ \\
\hline 3-vessel disease & $7686(69.8)$ & $3943(71.6)$ & $3743(67.9)$ & \\
\hline Isolated LM disease & $119(1.1)$ & $43(0.8)$ & $76(1.4)$ & \\
\hline LM and other vessel(s) & $3213(29.2)$ & $1523(27.7)$ & $1690(30.7)$ & \\
\hline
\end{tabular}

Data presented as number (\%) or mean \pm standard deviation. ASA, American Society of Anesthesiology; CCS, Canadian Cardiovascular Society; IABP, intra-aortic balloon pump; LM, left main; NYHA, New York Heart Association; PCI, percutaneous coronary intervention. *Performed within 72 hours of coronary artery bypass grafting.

\section{Propensity-Matched On-pump and Off-pump \\ Coronary Artery Bypass Grafting Cases for Incomplete Revascularization and Complete Revascularization}

For the propensity-matched on-pump CABG group ( $\mathrm{n}=7394$ ) (Figure 3, A), there was no statistically significant difference in mortality between IR and CR perioperatively $(2.62 \%$ vs 2.54 ; RR, 1.03 ; 95\% CI, $0.78-1.37$; $P=.83)$ or at 1 year $(6.95 \%$ vs $6.22 \% ; \mathrm{RR}, 1.12 ; 95 \%$ CI, $0.64-1.33 ; P=.21)$. However, a statistically significant difference in mortality was noted at 3 years $(11.94 \%$ vs $10.31 \%$; RR, 1.16; 95\% CI, 1.02-1.27; $P=.026), 5$ years $(17.78 \%$ vs $15.46 \%$; RR, $1.15 ; 95 \%$ CI, 1.04-1.27; $P=.0079)$, and 10 years $(31.25 \%$ vs $28.62 \%$; RR, 1.09 ; $95 \% \mathrm{CI}, 1.02-1.17 ; P=.014)$. The overall HR was 1.130 (95\% CI, 1.023-1.247).

For the propensity-matched off-pump CABG group $(\mathrm{n}=3572$ ) (Figure 3,B), there was no statistically significant difference in mortality between IR and CR perioperatively $(2.58 \%$ vs $1.90 \%$; RR, 1.36 ; 95\% CI, 0.88-2.11;
$P=.17)$, at 1 year $(6.87 \%$ vs $5.67 \% ; \mathrm{RR}, 1.21 ; 95 \% \mathrm{CI}$, $0.94-1.56 ; P=.13)$, at 3 years $(12.95 \%$ vs $11.20 \%$; RR, $1.16 ; 95 \% \mathrm{CI}, 0.97-1.38 ; P=.11)$, or at 5 years $(19.89 \%$ vs $17.95 \%$; RR, $1.11 ; 95 \% \mathrm{CI}, 0.97-1.27 ; P=.15)$. However, we noticed a significant difference in mortality between IR and CR at 10 years $(34.55 \%$ vs $29.52 \%$; RR, 1.17; 95\% CI, 1.06-1.29; $P=.0013)$. The overall HR was 1.156 (95\% CI, 1.000-1.335).

In the matched $\mathrm{CR}$ group, the patients undergoing onpump CABG had $3.51 \pm 0.71$ grafts per patient, whereas the patients undergoing off-pump CABG had $3.32 \pm 0.72$ grafts per patient. In the matched IR group, the patients undergoing on-pump CABG had $1.94 \pm 0.25$ grafts per patient, whereas the patients undergoing off-pump CABG had $1.76 \pm 0.43$ grafts per patient $(P<.05$ for both).

\section{DISCUSSION}

This study shows that IR is associated with poorer longterm survival than CR. Our findings support the value of performing thorough surgical revascularization whenever 


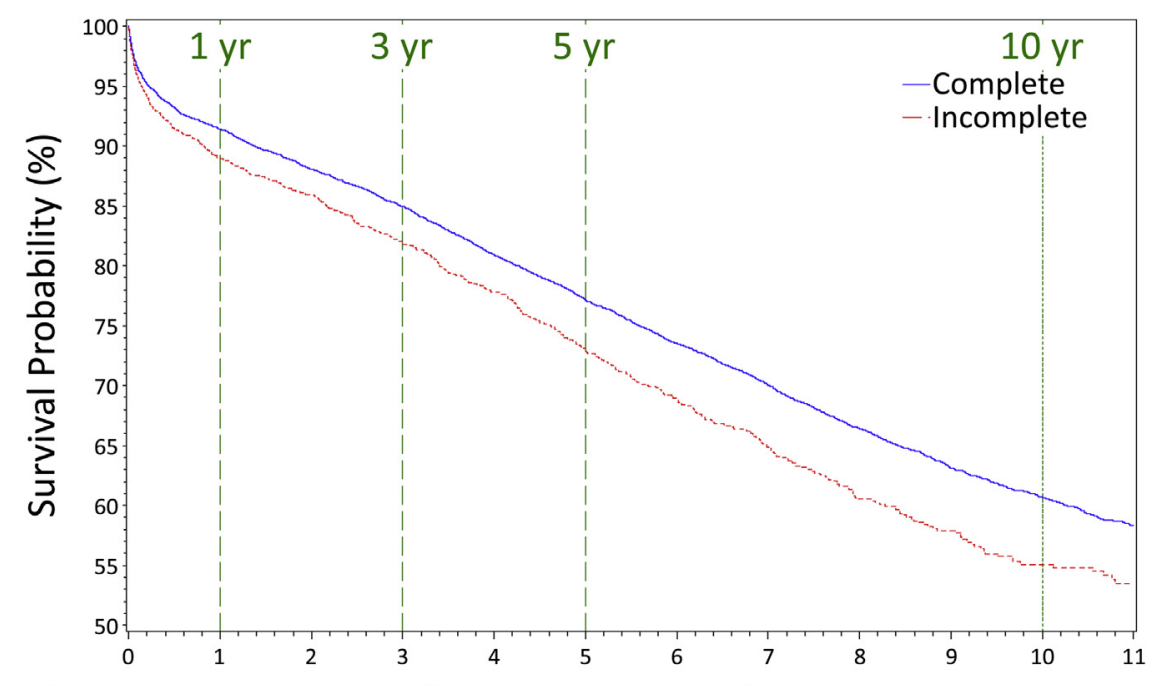

A Time Since Surgery (years)

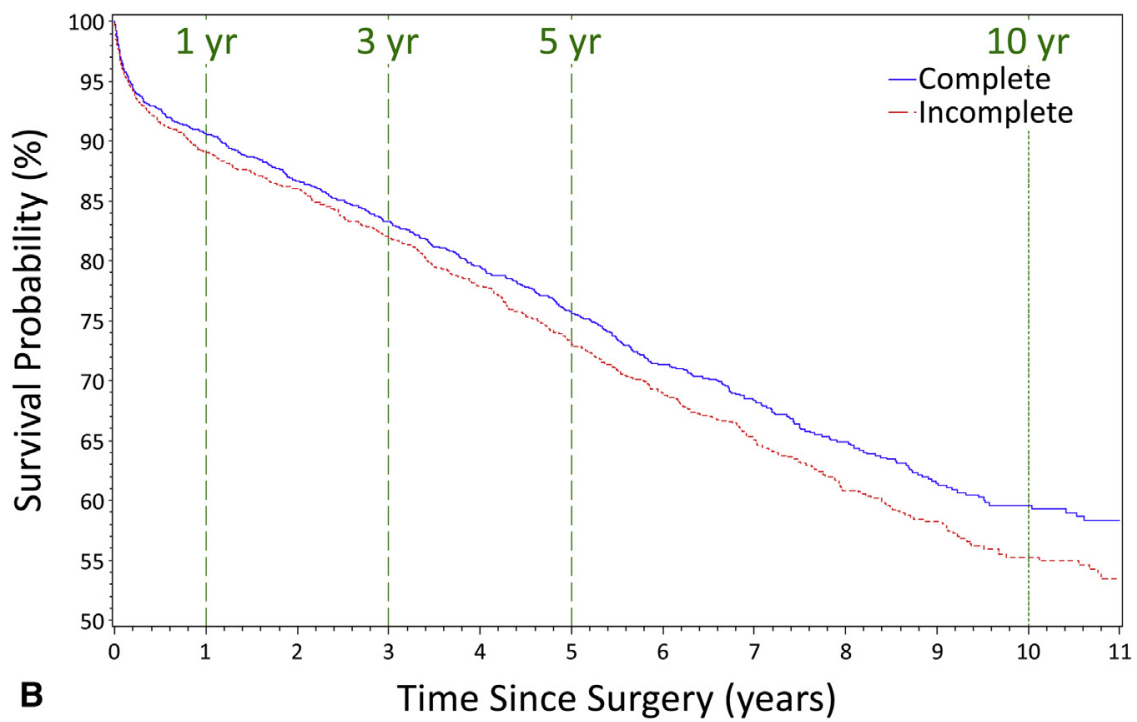

FIGURE 2. Survival of patients aged 70 years or more undergoing CR versus IR in the (A) unmatched and (B) propensity-matched cohorts.

possible. Lawrie and colleagues ${ }^{12}$ found that $\mathrm{CR}$ of the major arterial territories confers a survival advantage and concluded that the nature of residual disease postoperatively had a greater impact on survival than the nature of disease preoperatively.

However, CR is not always realistically achievable, for clinical or anatomic reasons. The common reasons for IR cited by Rastan and colleagues ${ }^{4}$ are small vessel diameter (63\% of cases), severely calcified target vessels $(25 \%)$, myocardial scarring $(3.9 \%)$, and other $(7.7 \%)$.

Other pertinent patient characteristics that influence the decision include older age, comorbidities, and the development of a procedural complication. Thus, in most CABG series, such decisions are made intraoperatively and not preoperatively. In contrast, the most frequently cited reason for IR in PCI is complete total occlusion of the target vessel.
Fortunately, IR due to complete total occlusion is far less prevalent for CABG than for PCI. ${ }^{13}$

Numerous studies show a survival benefit of CR over IR in patients undergoing CABG with severe multivessel $\mathrm{CAD}$, but most of these studies have had a limited number of patients. A study by Jones and colleagues ${ }^{14}$ enlisting 1238 patients found that the 5-year survival was significantly higher in patients with CR $(88.5 \%)$ than in those with IR $(83.5 \%)$ and emphasized CR to major arterial territories. Of note, more patients were free of angina after CR $(70 \%)$ than after IR (58\%). Kleisli and colleagues ${ }^{6}$ from Cedars-Sinai reported that CR was associated with a higher 5-year unadjusted survival rate than IR $(82.4 \%$ vs $52.6 \%)$ in a study with 1029 patients. Scott and colleagues ${ }^{15}$ from the Cleveland Clinic showed that, by itself, the left internal thoracic artery-LAD graft does not 

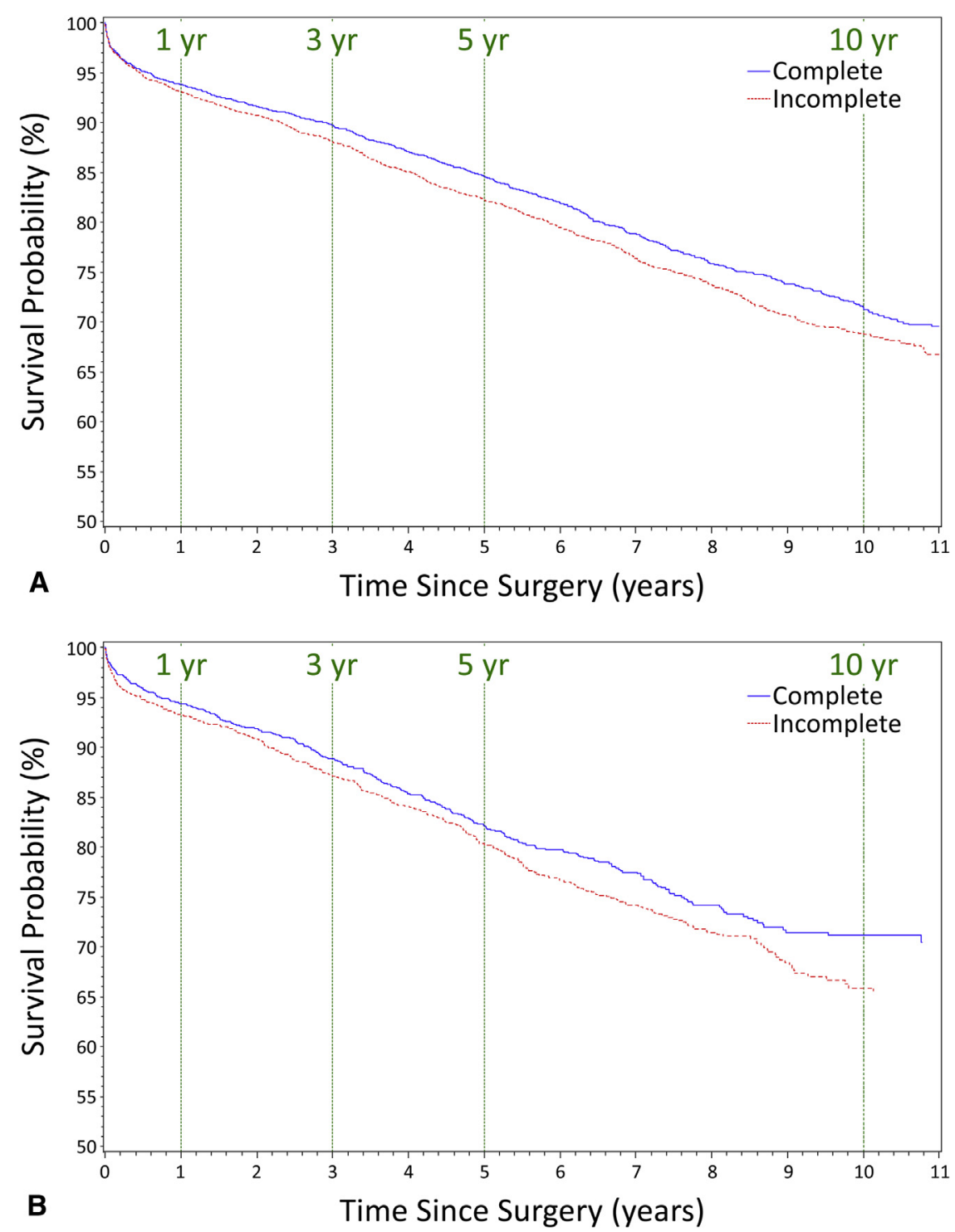

FIGURE 3. Survival of propensity-matched patients undergoing CR versus IR for (A) on-pump CABG and (B) off-pump CABG.

compensate for the presence of ungrafted disease in other non-LAD systems. More recently, a substudy of the Synergy Between Percutaneous Coronary Intervention with Taxus and Cardiac Surgery trial that included registry and randomized data showed, after multivariate analysis, that IR - and not the complexity of the coronary anatomyindependently predicted adverse 2-year outcomes. ${ }^{16}$

In contrast, several other studies have suggested that CR has no substantial benefit over IR for patients undergoing CABG. In a retrospective study of Coronary Artery Surgery Study Registry data, Bell and colleagues ${ }^{17}$ showed that the number of vessels bypassed in stable patients (CCS classes I-II group 1) did not significantly influence event-free survival as long as more than 2 vessels (including the LAD) were bypassed. However, even this study's authors noted that bypassing 3 or more vessels in patients who had severe symptoms (CCS classes III-IV group II) independently improved long-term survival, specifically in patients with left ventricular dysfunction (ejection fraction $<35 \%$ ).

In our study, we did not look specifically at more than 1 graft per major territory as a definition of CR. However, conclusions drawn from the Bypass Angioplasty Revascularization Investigation study by Vander Salm and colleagues $^{18}$ after 7 years of follow-up indicated that the construction of more than 1 venous graft to any major coronary system other than the LAD seemed to confer no long-term advantage and could be deleterious if multiple non-LAD insertion sites were chosen (ie, $>1$ graft to right coronary artery, circumflex, or ramus system). Likewise, an earlier study published by our group ${ }^{19}$ found similar rates of 30-day mortality, major adverse events, and 10-year survival in patients with multiple grafts to each major 
arterial territory and patients who received just 1 bypass to each major territory.

Elderly patients are underrepresented in large clinical trials. In 2 studies that focused on octogenarians, Kozower and colleagues ${ }^{20}$ and Aziz and colleagues ${ }^{21}$ found that CR carried a survival benefit over IR after adjustment for baseline variables. In contrast, analysis of a subset of data from Cedars-Sinai by Kleisli and colleagues ${ }^{6}$ showed no clinically significant benefit of CR in their octogenarians. Girerd and colleagues ${ }^{22}$ recently reported that IR did not adversely affect survival in patients aged 70 years or more. The reason cited was that older patients do not live long enough to benefit from CR. We noticed a significant advantage of $\mathrm{CR}$ over IR at 1, 3, 5, and 10 years in the unmatched group of patients aged 70 years or more, but among the propensity-matched patients, the survival advantage of CR only significantly manifested after 5 years postoperatively.

Our study also revealed a significant association between off-pump CABG and IR. This finding is supported by those of various other studies, most notably the Randomized On/ Off Bypass trial, ${ }^{23}$ which showed a higher incidence of IR with off-pump CABG than with on-pump CABG (17.8\% vs $11.1 \%, P<.0001)$. Furthermore, the 1 -year rate of the composite outcome of death, a repeat revascularization procedure, or a nonfatal myocardial infarction was higher for off-pump CABG than for on-pump CABG $(9.9 \%$ vs $7.4 \%, P=.04)$. Likewise, data indicating worse mid- and long-term survival with off-pump CABG were published by our group recently: Risk-adjusted mortality was higher in the off-pump group than in the on-pump group at 5 years (14.47\% vs $13.45 \%$; RR, 1.08 ; 95\% CI, $1.02-1.15)$ and 10 years ( $25.18 \%$ vs $23.57 \%$; RR, 1.07 ; 95\% CI, $1.03-1.12){ }^{24}$ These findings highlight 2 of the main pitfalls of off-pump CABG: IR and its consequence, worse long-term survival. Our subgroup analysis showed that fewer grafts were performed in the off-pump cohort than in the on-pump cohort. The survival advantage of $\mathrm{CR}$ is attenuated but still manifest in the off-pump group.

There has been mixed enthusiasm about hybrid coronary revascularization in the literature. ${ }^{25}$ In a study from Emory by Halkos and colleagues ${ }^{26}$ the need for repeat revascularization was higher after hybrid revascularization than after off-pump CABG (18/147 [12.2\%] vs 22/588 [3.7\%]; $P<.001)$. However, to date, there have been no randomized studies comparing traditional on-pump CABG with hybrid revascularization and the impact a hybrid approach may have on completeness of revascularization. A similar lack of consensus is seen with robotic totally endoscopic coronary artery bypass. In the largest study to date, by Bonaros and colleagues, ${ }^{27}$ single-vessel totally endoscopic coronary artery bypass was performed in 334 patients, double bypass was performed in 150 patients, triple bypass was performed in 15 patients, and quadruple bypass was performed in 1 patient. The low incidence of triple and quadruple bypasses in this series attests to the technical difficulty of this procedure and the potential challenge of accomplishing CR in patients with 3-vessel disease.

Most trials and registries show that patients who undergo IR have multiple comorbidities and unfavorable anatomy that could bias the data in favor of CR, because healthier patients may be more likely to undergo CR than IR. This is similar to what we found in our study, in which chronic obstructive pulmonary disease, peripheral vascular disease, cerebrovascular disease, and NYHA classes III/IV were more common in the unmatched groups, and the survival in the unmatched groups was better for $\mathrm{CR}$, as expected. However, after the groups were propensity-matched to minimize bias, CR still had a significant survival advantage. Therefore, CR should still be the goal when clinically prudent.

\section{Study Limitations}

One limitation of our study is that it is retrospective and therefore subject to bias that cannot be fully adjusted for by propensity matching. Although the number of distal anastomoses is captured, the database does not specify which conduit was used to bypass which target. We recognize that there are unusual circumstances under which more than 1 bypass would be performed on a major vascular territory, leaving behind an ungrafted territory, and that these instances would not have been captured in our database. However, if it were possible to capture such cases, doing so would be unlikely to change our findings. In fact, it would artificially inflate the size of the CR group, possibly causing our findings to underestimate the survival advantage of CR relative to IR. Another limitation is that approximately $99 \%$ of the patients are male because of the nature of the veteran population. In addition, we do not have data about myocardial viability or hemodynamic assessment of the coronary lesions. Such data and information about coronary size, coronary disease burden, and calcification have important implications relevant to surgical decisionmaking. The absence of data regarding major adverse cardiovascular events, including the need for reoperation and angina control, is also a limitation of this study. We also did not specifically look at the influence of total arterial revascularization and of arterial grafts other than the left internal thoracic artery on CR and IR. A strength of our study is the inclusion of a large number of patients whose data were obtained from a nonvoluntary, multi-institutional national database. The length of the follow-up and its completeness are unique in this particular area of investigation.

\section{CONCLUSIONS}

IR is more prevalent in patients undergoing off-pump $\mathrm{CABG}$ and is associated with decreased long-term survival, 
even in elderly patients. CR should be the goal when anatomically and physiologically feasible.

Stephen N. Palmer, PhD, ELS, contributed to the editing of the article.

\section{References}

1. Favaloro RG. Saphenous vein autograft replacement of severe segmental coronary artery occlusion: operative technique. Ann Thorac Surg. 1968;5:334-9.

2. Gruntzig AR. Transluminal dilatation of coronary artery stenosis. Lancet. 1978; 1:263.

3. Gossl M, Faxon DP, Bell MR, Holmes DR, Gersh BJ. Complete versus incomplete revascularization with coronary artery bypass graft or percutaneous intervention in stable coronary artery disease. Circ Cardiovasc Interv. 2012;5: 597-604.

4. Rastan AJ, Walther T, Falk V, Kempfert J, Merk D, Lehmann S, et al. Does reasonable incomplete surgical revascularization affect early or long-term survival in patients with multivessel coronary artery disease receiving left internal mammary artery bypass to left anterior descending artery? Circulation. 2009; 120:S70-7.

5. Serruys PW, Unger F, Sousa JE, Jatene A, Bonnier HJ, Schonberger JP, et al. Comparison of coronary-artery bypass surgery and stenting for the treatment of multivessel disease. N Engl J Med. 2001:344:1117-24.

6. Kleisli T, Cheng W, Jacobs MJ, Mirocha J, Derobertis MA, Kass RM, et al. In the current era, complete revascularization improves survival after coronary artery bypass surgery. J Thorac Cardiovasc Surg. 2005;129:1283-91.

7. Sarno G, Garg S, Onuma Y, Gutierrez-Chico JL, van den Brand MJ, Rensing BJ, et al. Impact of completeness of revascularization on the five-year outcome in percutaneous coronary intervention and coronary artery bypass graft patients (from the ARTS-II study). Am J Cardiol. 2010;106:1369-75.

8. Zimarino M, Calafiore AM, De Caterina R. Complete myocardial revascularization: between myth and reality. Eur Heart J. 2005;26:1824-30.

9. Faxon DP, Ghalilli K, Jacobs AK, Ruocco NA, Christellis EM, Kellett MA Jr, et al. The degree of revascularization and outcome after multivessel coronary angioplasty. Am Heart J. 1992;123:854-9.

10. Hillis LD, Smith PK, Anderson JL, Bittl JA, Bridges CR, Byrne JG, et al. 2011 ACCF/AHA Guideline for Coronary Artery Bypass Graft Surgery: a report of the American College of Cardiology Foundation/American Heart Association Task Force on Practice Guidelines. Circulation. 2011;124:e652-735.

11. The National Surgery Office. VHA Handbook 1102.01. Available at: http://www.va.gov/vhapublications/ViewPublication.asp?pub_ID=2861. Accessed December 3, 2013.

12. Lawrie GM, Morris GC Jr, Silvers A, Wagner WF, Baron AE, Beltangady SS, et al. The influence of residual disease after coronary bypass on the 5-year survival rate of 1274 men with coronary artery disease. Circulation. 1982:66:717-23.

13. Farooq V, Serruys PW, Garcia-Garcia HM, Zhang Y, Bourantas CV, Holmes DR, et al. The negative impact of incomplete angiographic revascularization on clinical outcomes and its association with total occlusions: the SYNTAX (Synergy
Between Percutaneous Coronary Intervention with Taxus and Cardiac Surgery) trial. J Am Coll Cardiol. 2013;61:282-94.

14. Jones EL, Craver JM, Guyton RA, Bone DK, Hatcher CR Jr, Riechwald N Importance of complete revascularization in performance of the coronary bypass operation. Am J Cardiol. 1983;51:7-12.

15. Scott R, Blackstone EH, McCarthy PM, Lytle BW, Loop FD, White JA, et al. Isolated bypass grafting of the left internal thoracic artery to the left anterior descending coronary artery: late consequences of incomplete revascularization. $J$ Thorac Cardiovasc Surg. 2000;120:173-84.

16. Mohr FW, Rastan AJ, Serruys PW, Kappetein AP, Holmes DR, Pomar JL, et al Complex coronary anatomy in coronary artery bypass graft surgery: impact of complex coronary anatomy in modern bypass surgery? Lessons learned from the SYNTAX trial after two years. J Thorac Cardiovasc Surg. 2011;141: $130-40$

17. Bell MR, Gersh BJ, Schaff HV, Holmes DR Jr, Fisher LD, Alderman EL, et al. Effect of completeness of revascularization on long-term outcome of patients with three-vessel disease undergoing coronary artery bypass surgery. A report from the Coronary Artery Surgery Study (CASS) Registry. Circulation. 1992; 86:446-57.

18. Vander Salm TJ, Kip KE, Jones RH, Schaff HV, Shemin RJ, Aldea GS, et al What constitutes optimal surgical revascularization? Answers from the Bypass Angioplasty Revascularization Investigation (BARI). J Am Coll Cardiol. 2002; 39:565-72.

19. Chu D, Bakaeen FG, Wang XL, Coselli JS, LeMaire SA, Huh J. The impact of placing multiple grafts to each myocardial territory on long-term survival after coronary artery bypass grafting. J Thorac Cardiovasc Surg. 2009;137:60-4.

20. Kozower BD, Moon MR, Barner HB, Moazami N, Lawton JS, Pasque MK, et al. Impact of complete revascularization on long-term survival after coronary artery bypass grafting in octogenarians. Ann Thorac Surg. 2005;80:112-7.

21. Aziz A, Lee AM, Pasque MK, Lawton JS, Moazami N, Damiano RJ Jr, et al. Evaluation of revascularization subtypes in octogenarians undergoing coronary artery bypass grafting. Circulation. 2009;120:S65-9.

22. Girerd N, Magne J, Rabilloud M, Charbonneau E, Mohamadi S, Pibarot P, et al. The impact of complete revascularization on long-term survival is strongly dependent on age. Ann Thorac Surg. 2012;94:1166-72.

23. Shroyer AL, Grover FL, Hattler B, Collins JF, McDonald GO, Kozora E, et al. On-pump versus off-pump coronary-artery bypass surgery. N Engl J Med. 2009:361:1827-37.

24. Bakaeen FG, Chu D, Kelly RF, Ward HB, Jessen ME, Chen GJ, et al. Performing coronary artery bypass grafting off-pump may compromise long-term survival in a veteran population. Ann Thorac Surg. 2013;95:1952-60.

25. Murphy GJ, Bryan AJ, Angelini GD. Hybrid coronary revascularization in the era of drug-eluting stents. Ann Thorac Surg. 2004;78:1861-7.

26. Halkos ME, Vassiliades TA, Douglas JS, Morris DC, Rab ST, Liberman HA, et al. Hybrid coronary revascularization versus off-pump coronary artery bypass grafting for the treatment of multivessel coronary artery disease. Ann Thorac Surg. 2011:92:1695-702

27. Bonaros N, Schachner T, Lehr E, Kofler M, Wiedemann D, Hong P, et al. Five hundred cases of robotic totally endoscopic coronary artery bypass grafting: predictors of success and safety. Ann Thorac Surg. 2013;95:803-12. 


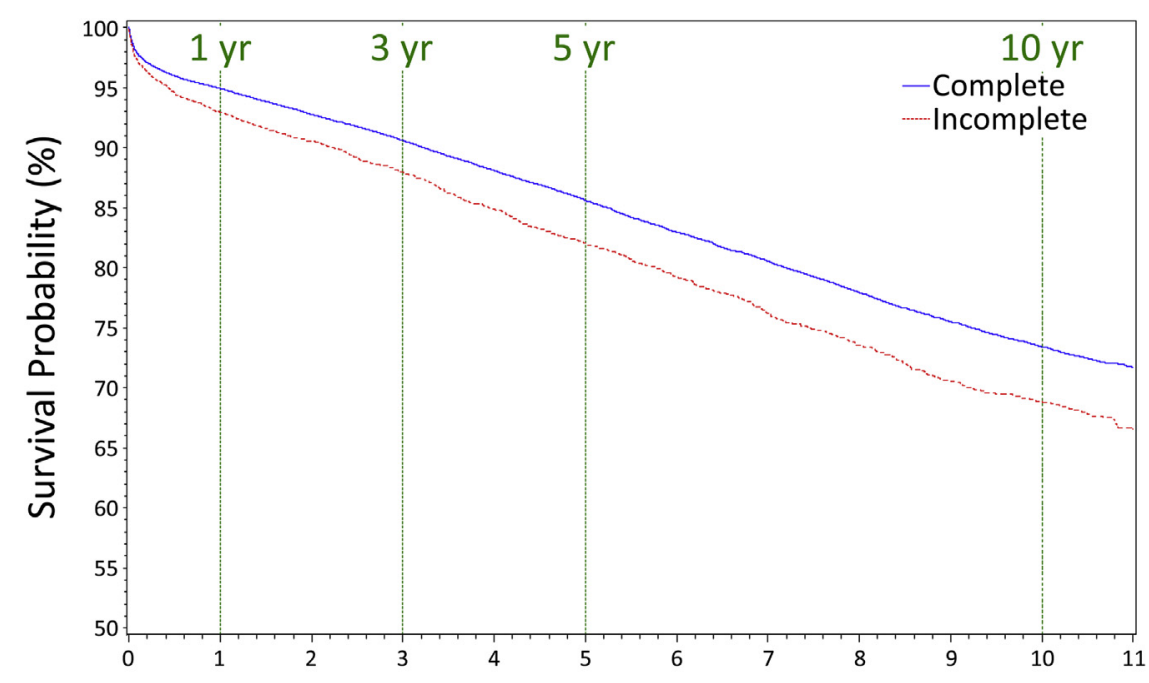

A Time Since Surgery (years)

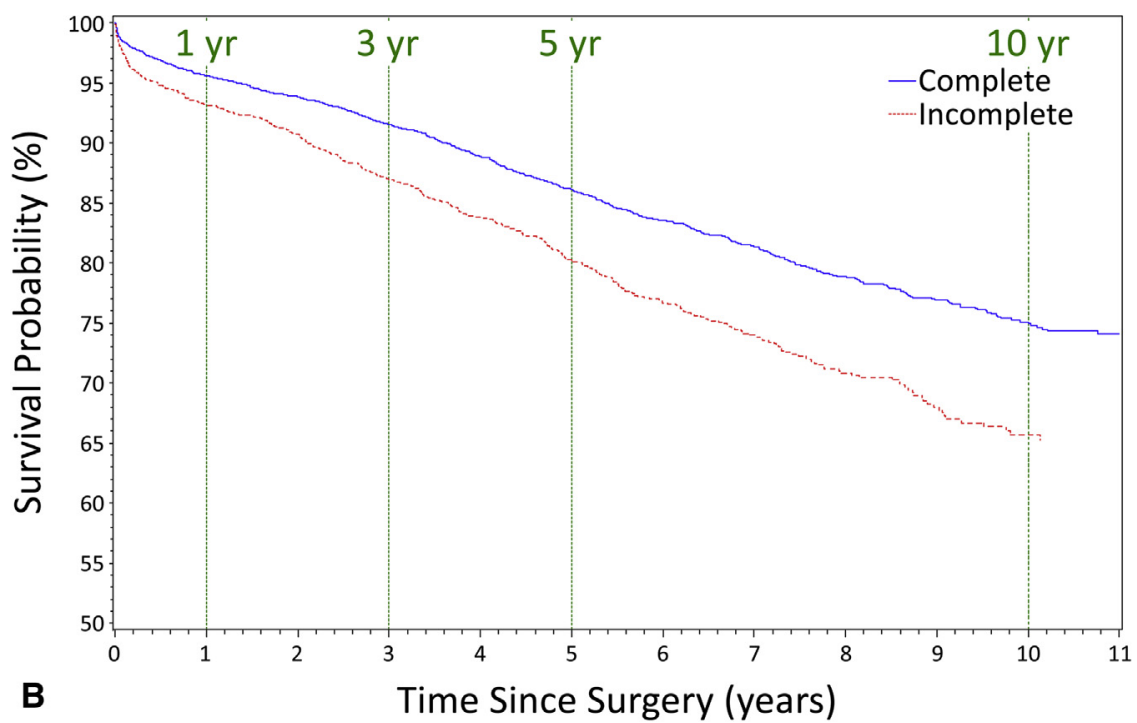

FIGURE E1. Survival of unmatched patients who underwent CR versus IR for (A) on-pump CABG and (B) off-pump CABG. 